\title{
Hemolytic Disease of the Newborn: A Review of Current Trends and Prospects
}

\author{
Akshay Kiran Myle $\mathbb{D}^{1,2}$ \\ Ghanim Hamid Al- \\ Khattabi $\mathbb{D}^{2}$ \\ 'Department of Clinical Research, \\ General Medicine, Pharmacology, \\ Integrative Medicine, Clinical Researcher. \\ National Institute of Medicine Sciences, \\ Poduru Mandalam City, Andhra Pradesh \\ State, India; ${ }^{2}$ Preventive Medicine and \\ Public Health, Ministry of Health, Makkah \\ City, Kingdom of Saudi-Arabia
}

\begin{abstract}
Hemolytic disease of the newborn (HDN), also known as Erythroblastosis fetalis, is a hemolytic condition that predominantly affects rhesus-positive fetuses and infants born to rhesus-negative mothers. The pathophysiology of HDN begins with maternal antibodies attacking fetal red blood cells following alloimmunization due to rhesus or ABO incompatibility between the maternal and fetal blood. Previously, HDN was known to cause fetal death in $1 \%$ of all pregnancies, but with the advent of immunoprophylactic therapies, the condition can be currently fairly well managed with fewer complications if diagnosed early. Diagnosis calls for extensive history taking, physical examination, serological studies, and imaging modalities such as pelvic ultrasound scans. To prevent the disease, earlier intravenous immunoglobulin (IVIG) should be given to pregnant Rh- women who have not been sensitized. It is also vital to understand prospective complications such as severe hyperbilirubinemia and develop appropriate remedies. Because of its great incidence and nature, HDN has been thoroughly explored, and more studies are being conducted each year, revealing new insights about the condition. This review covers the disorder's etiology, diagnosis, and management, including the most current findings as of 2021, as well as trends and prospects, to help in future research and evidence-based medical practice.
\end{abstract}

Keywords: alloimmunization, fetomaternal hemorrhage, hemolysis, immunoprophylaxis

\section{Introduction}

Hemolytic disease of the newborn (HDN), also known as Erythroblastosis fetalis, is a hemolytic disorder that primarily affects Rhesus positive $(\mathrm{Rh}+)$ fetuses and newborns born to Rhesus negative (Rh-) mothers. A French midwife first described the disorder in 1609; however, it was not until the 1950s when the underlying cause was clarified. ${ }^{1}$ The pathogenesis of HDN begins with the attack of fetal red blood cells (RBCs) by maternal antibodies due to incompatibility of maternal and fetal blood based on the Rhesus and ABO antigen systems. Usually, when the first child inherits paternal D antigen, whose inheritance has been shown to follow an autosomal dominant pattern, and there occurs an event that leads to mixing of maternal and fetal blood, the mother starts producing anti-D antibodies through a process referred to as alloimmunization, as she lacks the D antigen. ${ }^{2}$ Immunologically, antibody secretion initially starts with IgM, which cannot cross the placental barrier, but is then followed by isotype switching, which produces IgG antibodies. IgG antibodies can cross the placental barrier, and they do so during the second and or subsequent pregnancies, attacking the fetal RBCs and causing hemolysis and associated complications such as Hydrops fetalis and jaundice. ${ }^{3}$ Although, the $\operatorname{IgG}$
Correspondence: Akshay Kiran Myle Email myleakshaykiran@gmail.com 
antibodies can enter fetal circulation through fetomaternal hemorrhage (FMH) as well.

HDN has been estimated to affect 3 to 8 for every 100,000 patients yearly. Before developing anti-D prophylaxis, it was responsible for fetal loss in $1 \%$ of all pregnancies. ${ }^{4}$ The occurrence of HDN is directly correlated with the inheritance pattern in females that results in the absence of the Rhesus (D) antigen; however, the incidence of HDN is seen to vary with ethnicity. ${ }^{5}$ For instance, it has been found that whites have the highest prevalence, and Asians and American Indians have the lowest, as illustrated in Table 1. Furthermore, among the Rh antigens in existence, the most immunogenic one is the D antigen. It is approximated that about $10 \%$ of pregnant white women are $\mathrm{Rh}$ incompatible.

Because of its high prevalence and nature, HDN has been extensively studied, and more studies continue to be done each year, uncovering more concepts regarding the disorder. This review summarizes the disorder in terms of etiology, diagnosis, and management, incorporating the most recent findings as of 2021 and trends and prospects to aid in further research evidence-based medical practice.

\section{Background}

The knowledge of blood group systems is essential in clinical practice, especially for hematological disorders. The primary blood group systems in humans include the ABO and Rhesus systems. In 1904, Karl Landsteiner discovered the human blood groups. He characterized them using the Landsteiner law, which states that the corresponding antibodies are present in the plasma for each blood group antigen not present on the RBCs. ${ }^{6}$ However, this is not the case with the rhesus antigen - antigen D. Typically, anti-D antibodies are absent in both $\mathrm{Rh}+$ and $\mathrm{Rh}$ - individuals, but when Rh- individuals are exposed to the $\mathrm{D}$ antigen, they start secreting the corresponding antibodies. Therefore, the presence of both $\mathrm{D}$ antigens and anti-D antibodies in the same person can lead to RBC agglutination and hemolysis, which is the basis of $\mathrm{Rh}$ incompatibility. ${ }^{7} \mathrm{ABO}$ incompatibility also follows the same pattern, and because of that, care has to be taken when doing blood transfusions and tissue transplants. In almost all of the cases of HDN, the underlying cause is usually $\mathrm{Rh}$ or $\mathrm{ABO}$ incompatibility between the mother and the fetus, when alloimmunization occurs, and the maternal antibodies start attacking fetal RBCs. Maternal antibodies reach the fetus when $\operatorname{IgG}$ antibodies, following antibody isotype switching, cross the placenta and enter the fetal circulation or through FMH. $^{2,8}$

A 2017 review by Ree et al stated a global shift in HDN from $1 \%$ with a death rate of $50 \%$ before introducing Rh- immunoprophylaxis in 1968 to $0.5 \%$ after its introduction. The incidences decreased further to $0.1 \%$ with the introduction of antepartum $\mathrm{Rh} \mathrm{D}$ immunoprophylaxis in 1970. ${ }^{9}$ Although there is sufficient RhD immunoprophylaxis, it is still approximated that between 1 to 3 of a thousand women who are Rh- still develop alloimmunization presently. ${ }^{10}$ While a larger proportion of HDN is caused by $\mathrm{Rh}$ incompatibility, the Rh- phenotype is less common, although it occurs more in some ethnic groups and races than others. For instance, epidemiological studies have revealed that $15 \%$ of whites are Rh- while only $1 \%$ of Asians are Rh- (Table 1).

The mechanisms mentioned above can explain the pathophysiology of HDN. According to published research, $\mathrm{ABO}$ mismatch affects 15 to $25 \%$ of all pregnancies. However, only $1 \%$ of people will develop HDN. ${ }^{11}$ The response caused by ABO incompatibility is modest, most likely due to the expression of $\mathrm{ABO}$ blood type antigens and their presentation in several organs. With FMH, the maternal antibodies are secreted following mixing of the maternal and blood, and the most commonly involved antigen is the Rhesus/D antigen. ${ }^{12}$

Antigens in fetal blood (mainly Rh-positive inherited from the paternal side) are not found in maternal blood, which is Rh-. IgM-type antibodies are the first to form due to FMH, and because they cannot cross the placenta, the first pregnancy survives, leaving behind an already sensitized immune system. ${ }^{2}$ In the event of rhesus factor incompatibility, the fetus is at risk. At a later stage, in subsequent pregnancies, the mother's rhesus antibodies may attack the fetus's antigens, resulting in alloimmune hemolysis in the fetus. As a result, a significant amount of bilirubin is freed from the

Table I Prevalence of HDN According to Ethnic Groups

\begin{tabular}{|l|l|}
\hline Ethnicity & Prevalence by Percentage (\%) \\
\hline Africans & 4 \\
\hline African-Americans & 8 \\
\hline Whites & $15-16$ \\
\hline Eurasians & 2.4 \\
\hline Asians & $<1$ \\
\hline Basque (Spain/France) & $30-35$ \\
\hline
\end{tabular}

Note: Data from. ${ }^{5}$ 
fetus's hemoglobin breakdown. The placenta transports them to the maternal circulation. They are worked on and removed by the mother once they enter her system. ${ }^{13,14}$ Nonetheless, problems may occur, increasing serum bilirubin levels, resulting in severe jaundice.

The least afflicted newborns may have mild anemia and just hyperbilirubinemia due to the ongoing effect of rhesus antibody hemolysis. Kernicterus occurs in roughly $25 \%$ of instances of fetal hyperbilirubinemia. ${ }^{15,16}$ Kernicterus is a condition caused by the buildup of bilirubin in the tissues of the central nervous system. It usually happens in the days following birth. Surviving kernicterus is typically not considered a true survival because survivors may still have developmental retardation, hypotonia, and hearing loss. ${ }^{17}$ As a result, the symptoms mentioned earlier should be sought during the physical examination of the newborn.

As with any diagnosis, the value of history and physical examination cannot be overstated. Prior history of HDN or hydrops fetalis, chorionic villus sampling, amniocentesis, antepartum hemorrhage, miscarriages, abortions, and maternal blood transfusions are all risk factors for FMH. ${ }^{18}$ Blood testing throughout the first trimester is very important. Pregnant women with blood type O should be closely examined during and after birth. It is advised that the blood type of their baby be identified as soon as possible after birth. A lady with $\mathrm{Rh}$ - blood type gets the Rosette test to rule out the potential of HDN. ${ }^{19}$ This test is capable of identifying alloimmunization caused by even little FMH. If there is clinical suspicion of FMH ( $>30 \mathrm{~mL}$ blood), another test known as Kleihauer-Betke acid elution is performed. ${ }^{19}$ The amount of fetal RBCs in the woman's blood is determined quantitatively by this test. A similar test can be used to evaluate whether another Rh IgG injection is necessary. Pelvic ultrasound of a pregnant woman with probable $\mathrm{Rh}$ incompatibility is also important in diagnosing HDN, and it is often restricted to the pelvis. ${ }^{13,20}$ Other causes of newborn jaundice and anemia must be ruled out before a definitive diagnosis of HDN can be made. As a result, traditional tube techniques and the Gel card approach can be used for diagnosis. ${ }^{21-23}$ The direct and indirect Coombs tests are two conventional techniques. The red blood cells are rinsed and centrifuged with antihuman antiglobulin in the indirect Coombs test. Agglutination occurs when immunoglobulins or complement factors are fixed to the surface of RBCs in vitro, indicating a positive test. ${ }^{24,25}$ The indirect Coombs test is used in prenatal screening to detect prenatally generated antibodies and testing before blood transfusion. It utilizes the patient's serum, which is incubated with foreign red blood cells of known antigenicity. The Coombs reagent is next added, and if agglutination occurs, the test is positive. The serum is incubated in the Red blood cell test, and the response occurs within a microtube. Non-agglutinated cells move through a gel matrix (Sephadex) to create a bottom, while bigger agglutinates remain on top. ${ }^{26}$ Singh et al discovered that the sensitivity and specificity of the two approaches were equivalent in comparative research comparing and contrasting conventional methods and gel card technology. On the other hand, the gel card technique was less time-consuming, more dependable, and the findings could be documented. ${ }^{27}$

The disease was responsible for significant morbidity and mortality for a long time until preventative and therapeutic techniques like phototherapy, intrauterine transfusion, exchange transfusion, and amniocentesis were established. Since then, the prevalence has decreased, with a perinatal survival rate of more than $90 \%{ }^{28}$ Phototherapy is the first-line treatment method and has been the treatment of choice for more than 30 years due to fewer side effects and its efficacy in treating preterm infants. $^{29,30}$ The two forms of treatment offered are prophylactic and therapeutic phototherapy. Light emission within a wavelength range of $460-490 \mathrm{~nm}$ in the bluegreen range, maximum exposure to the infant's body, and adequate irradiance all contribute to this modality of treatment. $^{29,31,32}$ Hyperbilirubinemia caused by HDN is mostly treated with phototherapy and, on rare occasions, exchange transfusion. In a 2004 research by pediatricians (AAP), recommendations were made that HDN was possible for children with the following birth weights: $2000 \mathrm{~g}$, 2000 to $2499 \mathrm{~g}$, and bilirubin level $>171 \mathrm{umol} / \mathrm{L}$ (10 mg/ $\mathrm{dL}), 2500 \mathrm{~g}$, and $222 \mathrm{umol} / \mathrm{L}(13 \mathrm{mg} / \mathrm{dL})$ respectively. ${ }^{13,33}$

On the other hand, exchange transfusion is suggested for extremely anemic newborns and includes replacing the baby's RBCs with antigen-negative RBCs. ${ }^{34}$ In addition, in fragile patients, a blood transfusion using ABO-matched packed RBCs may be explored. ${ }^{35}$ Studies have also found that exchange transfusion is safe, with death rates ranging from $0.53 \%$ to $4.7 \%$ per child. ${ }^{29,36}$ The side effects of exchange transfusion are severe cardiorespiratory effects, catheter and blood product problems, metabolic derangements, necrotizing enterocolitis, and intestinal perforation. Over the previous two decades, the hazards of exchange transfusions have been reported to reach up to $74 \%$. However, the negative impact is roughly $31 \%$. For more than 21 years, there has been no growth in morbidity and mortality, according to Steiner et al. ${ }^{37}$ Intravenous immunoglobulin (IVIG) has been proposed as an alternative for 
exchange transfusion and phototherapy, with some advantages. However, prophylaxis with intravenous immunoglobulin remains debatable Several studies have found that IVIG has no advantage over exchange transfusion, a more intrusive procedure. ${ }^{9,30,38}$

Furthermore, clinical data show IVIG has failed to treat a large number of ABO-HDN patients. ${ }^{29,34}$ IVIG comprises antibodies, primarily IgG, IgM, IgA, and IgE, and electrolytes, sugar, cytokines, albumin, and solvents. The proposed mechanisms of IVIG are that it inhibits antibody neutralization in newborns with $\mathrm{ABO}-\mathrm{HDN}$, therefore lowering the risk. ${ }^{39,40}$ However, all of the above therapeutic techniques have side effects. Therefore, prevention is still essential in decreasing morbidity and mortality. Also, the concern about the severity of problems and the risk of mortality has required early screening and preventative strategies during prenatal care appointments. In addition, sensitizing procedures including abortion, amniocentesis, and chorionic villus sampling should be followed with anti-D immunoglobulin prophylaxis. ${ }^{41,42}$

According to Neil Murray of ADC Fetal and Neonatal, it has been discovered that the spectrum of the HDN has broadened since its first identification. ${ }^{43}$ Previously, the situation remained constant, resulting in excessive fetal and neonatal hemolysis, hyperbilirubinemia, and severe anemia. However, with the use of standard postnatal prophylactic anti-D immunoglobulin for Rh- mothers, this condition has been significantly decreased. This therapy has shown to be one of the most effective post-modern perinatal care options. ${ }^{41}$ Blood transfusions are required for anemic newborns, and the blood must be ABO-matched and packed with red blood cells. Furthermore, the blood must be type $\mathrm{O}$ and Rh-and leukodepleted and irradiated. ${ }^{19}$ All of these should be present throughout the delivery.

\section{Etiology}

HDN is commonly caused by the incompatibility of the mother's and the baby's blood. Suppose the baby's blood crosses over and reaches the mother's incompatible RBCs; the mother's immune system perceives the fetal antigens as non-self and fights them by releasing antibodies that do not hesitate to attack and destroy them. ${ }^{2}$ Usually, the crossover occurs through the placenta during pregnancy or delivery. This leads to severe complications in the baby's system, which may even lead to the ultimate demise of the baby. However, the immune system of the mother does not get rid of the antibodies. Still, it develops immunological memory, which can cause the secretion of more antibodies upon re-exposure to the antigen. As a result, HDN is likely to occur in the second and the subsequent pregnancies, even after a miscarriage or abortion. ${ }^{8}$

\section{Diagnosis}

\section{Laboratory Studies}

To diagnose and manage pregnant women with HDN, extensive laboratory and imaging practice is required. HDN is clinically indicated by: (1) rapid and severe hyperbilirubinemia or persistent hyperbilirubinemia; and (2) hemolysis on blood film results. ${ }^{44}$ It should also be noted that the extent of hematopoiesis affects the severity of the disorders.

Also, clinical conditions such as anemia, thrombocytopenia, and neutropenia are often observed in patients. The anemia can be accurately estimated using arteriole samples instead of capillary blood. Thrombocytopenia commonly accompanies exchange transfusions. It results from poor blood platelets formation and when the production is suppressed in favor of erythropoiesis. Neutropenia is mostly observed after intrauterine transfusion. It is commonly associated with increased circulating cytokines (such as granulocyte-macrophage colony-stimulating factor) and reticulocytosis, ie, increased nucleated RBCs and cell fragmentation. ${ }^{36,45}$ In addition, Rh-HDN peripheral blood smears usually show polychromasia, anisocytosis, erythroblasts, and no spherocytes. ${ }^{4}$

Furthermore, a serological test needs to be done to verify the positivity of the HDN. The results of this test may show that the baby is either directly or indirectly impacted by the variation in the mother's Coombs and antibodies. According to a recent study, the positive impact of the natural antibody test finding is related to a predictive value of $23 \%$ and a sensitivity of $86 \%{ }^{46}$ If the neonatal hemolytic syndrome is caused by antic, the direct antibody test may be negative. As a result, it is suggested that a diagnosis be made only when the indirect Coombs test has shown certainty. Table 2 summarizes the laboratory tests utilized in the diagnosis of HDN and their expected results.

\section{Imaging Studies}

During pregnancy, the fetus should be screened for maternal red cell alloantibodies. Ultrasound should also be used, especially when intravenous transfusion is performed. ${ }^{48}$ Maternal blood samples for $\mathrm{ABO}, \mathrm{Rh}$ group, and red cells should be tested throughout this phase. If alloantibodies capable of causing HDN are found, a laboratory test 
Table 2 Laboratory Tests and Results for HDN

\begin{tabular}{|l|l|l|l|}
\hline \multicolumn{2}{|l|}{ Mother's Sample } & \multicolumn{2}{|c|}{ Baby's Sample } \\
\hline Test & Result & Test & Result \\
\hline $\begin{array}{l}\text { ABO/Rh } \\
\text { Determination }\end{array}$ & $\begin{array}{l}\text { A (Rh } \\
\text { D positive) }\end{array}$ & $\begin{array}{l}\text { ABO/Rh } \\
\text { Determination }\end{array}$ & $\begin{array}{l}\text { A (Rh } \\
\text { D positive) }\end{array}$ \\
\hline $\begin{array}{l}\text { Antibody } \\
\text { Screening }\end{array}$ & Positive & $\begin{array}{l}\text { Polyspecific } \\
\text { DAT }\end{array}$ & Positive \\
\hline $\begin{array}{l}\text { Antibody } \\
\text { Identification }\end{array}$ & Anti-c testing & $\begin{array}{l}\text { IgG/C3 } \\
\text { Coombs }\end{array}$ & $\begin{array}{l}\text { IgG positive/ } \\
\text { C3d-negative }\end{array}$ \\
\hline Antigen Typing & $\begin{array}{l}\text { Negative for } \\
\text { "c" antigen }\end{array}$ & Elution & Positive \\
\hline
\end{tabular}

Note: Data from. ${ }^{47}$

should be performed to validate the findings. The father's phenotype should be established to help estimate the chance of a newborn bearing the appropriate red cell antigen. ${ }^{49}$ Once fetal $\mathrm{Rh}$ positivity is established, fetal surveillance can be done by serial maternal pelvic ultrasounds, umbilical artery, and middle cerebral artery (MCA) dopplers. MCA dopplers are often utilized to screen for anemia in $\mathrm{Rh}+$ fetuses. They are done every 1-2 weeks from the 24th week of gestation. This kind of monitoring checks for peak systolic velocity (PSV), as it is always bound to increase in anemia. ${ }^{50}$ Fetal ultrasounds are usually utilized to check for fetal ascites, soft-tissue edema, scalp edema, pleural effusion, cardiomegaly, and hepatomegaly with portal hypertension if the fetus is heavily affected. ${ }^{51}$

\section{Patient Care and Prevention}

When the testing results indicate anemia in the uterus, group $\mathrm{O}$ negative blood transfusion should begin. The transfused blood type $\mathrm{O}$ negative should be crossmatched with maternal blood. This procedure is best completed between the ages of 16 and $18 . .^{52}$ Furthermore, intravenous transfusion under ultrasound monitoring should be used since it is simple in a hydropic fetus and does not create more problems than intraperitoneal fetal transfusion. ${ }^{53}$ Neonates should be regularly watched after birth to look for the emergence of any late anemia between 6 and 8 weeks. This amounts to $50 \%$ of the total. However, around $25 \%$ of the newborns have the typical illness, which necessitates transfusion. ${ }^{54}$ If severe HDN is expected, the delivery should be performed by a specialized pediatrician who has received neonatal resuscitation training, and fresh blood should be made available. The earlier the IVIG is given, the lower the risk of hemolysis and the requirement for exchange transfusion. ${ }^{55}$ To prevent HDN, IVIG should be given to all $\mathrm{Rh}$ - women who have not already been sensitized.

To improve health care results, a solid clinician-patient connection is required. Collaboration among members of an interprofessional team, which mostly consists of an obstetrician, a primary physician, and nurses, is also needed. Because this condition is avoidable, doctors must accurately examine and screen both mother and father during the first trimester and closely monitor antibody titers in Rh- females. These antibody levels should be less than 1:16, and if they are higher, invasive testing is performed to treat them appropriately. ${ }^{56}$ Critical monitoring of the fetus using MCA Doppler provides an accurate picture of fetal anemia, determining if an intrauterine transfusion is required or not.

\section{Potential Complications of Exchange and Transfusion}

Several complications may be experienced during a blood transfusion. It is critical to have an initial understanding of such prospective difficulties to establish remedies and handle them. Severe hyperbilirubinemia, which is unpredicted by maternal prenatal antibody screening; persistent hyperbilirubinemia; and $\mathrm{ABO}$ incompatibility, are a few of the complications. ${ }^{57}$ Furthermore, if a mother with antibodies needs a blood transfusion, she risks a future transfusion response. One alternative solution is to tell medical staff and physicians about her past diagnosis. This may assist doctors in administering the correct diagnosis and taking care of the patient. A fetus may develop mild to severe anemia and even jaundice during pregnancy. In addition, if the baby's organs are incapable of dealing with anemia, it is at risk of developing hydrops fetalis. ${ }^{58}$ The newborn may develop kernicterus, the most severe type of hyperbilirubinemia, at birth. Potential consequences in certain situations include bacterial and viral infections such as HIV, hepatitis, and malaria. Metabolic problems such as acidosis, hypocalcemia, and hypernatremia might also occur. ${ }^{59}$

Furthermore, certain vascular problems such as thrombosis, neutralizing enterocolitis, and umbilical vessel perforation may occur. Hypothermia is also an accompanying systemic danger that severely affects the tissues. ${ }^{60}$ Table 3 summarizes some of the aforementioned potential risks. 
Table 3 The Potential Complications Associated with HDN

\begin{tabular}{|l|l|}
\hline Outcome & Number (\%) \\
\hline Cardiovascular & \\
Bradycardia (mild) & $\mathrm{I}(2)$ \\
Bradycardia needing CPR & $\mathrm{I}(2)$ \\
Limb cyanosis & $\mathrm{I}(2)$ \\
\hline Metabolic & \\
Hypomagnesemia & $2(4)$ \\
Hyperglycemia & $7(15)$ \\
\hline Hematologic & \\
Thrombocytopenia & $15(32)$ \\
Platelet Transfusion & $3(7)$ \\
Anemia & $11(23)$ \\
PRBCs Transfusion & $4(8)$ \\
\hline Follow-up and neurological complications & \\
Post-discharge visit for at least I time & $35(78)$ \\
Post-discharge follow-up for more than one year of age & $25(52)$ \\
Developmental delay and seizures & $1(4)$ \\
Spasticity & $1(4)$ \\
Hearing Deficit & $1(4)$ \\
\hline
\end{tabular}

Note: Data from. ${ }^{61,62}$

\section{Trends and Future Prospects}

Blood typing using molecular methods is becoming more common as molecular testing becomes more widely used in medicine. Serological probes do not always correctly identify the $\mathrm{RhD}$ type in some individuals. Weak D phenotypes seem to be the most common genetic background that accounts for this serological typing problem. Scholars have recently advocated using $\mathrm{RhD}$ genetic testing for patients with a weak D phenotype to obtain accurate and actionable results for $\mathrm{RhD}$ blood typing and $\mathrm{Rh}$ Ig administration. ${ }^{63-65}$

There is still a vast capacity for improving HDN's understanding and management in both developed and developing countries. Universal research-backed guidelines regarding $\mathrm{RBC}$ antigen matching transfusion techniques for women before pregnancy or during intrauterine transfusion would be a good place to start. ${ }^{66}$ A critical area that needs more research is the mechanism of action of Rh immunoglobulin. We believe that a proper understanding of the roles of RBC clearance, antigen masking, modulation, and immune suppression might help develop innovative preventive prophylaxis during gestation for vaccination against $\mathrm{Rh}$ and non-Rh antigens. Proper understanding of the roles of fetal RBC clearance, antigen masking, antigen modulation, and immune suppression in the efficacy of $\mathrm{Rh}$ immunoglobulin may assist in developing innovative preventive treatments during pregnancy for vaccination against $\mathrm{RhD}$ and non-RhD antigens. Furthermore, more understanding of the relevance of anti-RhD or other alloantibody glycosylation patterns may be useful in the development of novel treatments and in predicting the clinical significance of current maternal alloantibodies. Another area of need is developing treatments other than intrauterine infusions to alleviate maternal alloantibodies' risks to the fetus.

\section{Conclusion}

HDN is a complex multidimensional condition with unique technical issues during numerous crucial developmental stages of the prenatal and neonatal eras. Advances in maternal-fetal medicine, including the development of IVIG, IUT, and noninvasive fetal genetic testing, have resulted in significant improvements in HDN outcomes and the avoidance of maternal allosensitization. Future advancements in blood typing and noninvasive testing will help women and their children with blood group incompatibility. Also, more attention should be given to the ethnic groups and races that are more at risk.

\section{Disclosure}

The authors report no conflicts of interest in this work.

\section{References}

1. Jackson ME, Baker JM. Hemolytic disease of the fetus and newborn: historical and current state. Clin Lab Med. 2021;41(1):133-151. doi:10.1016/j.cll.2020.10.009

2. Gupta GK, Balbuena-Merle R, Hendrickso JE, Tormey CA. Immunohematologic aspects of alloimmunization and alloantibody detection: a focus on pregnancy and hemolytic disease of the fetus and newborn. Transfus Apheresis Sci. 2020;10:102946.

3. Alaqeel AA. Hyporegenerative anemia and other complications of rhesus hemolytic disease: to treat or not to treat is the question. Pan Afr Med J. 2019;32:134.

4. Routray SS, Behera R, Mallick B, et al. The spectrum of hemolytic disease of the newborn: evaluating the etiology of unconjugated hyperbilirubinemia among neonates pertinent to immunohematological workup. Cureus. 2021;13(8):110.

5. Doll P. Hemolytic disease of newborn: symptom and causes. Pediatrics. 2021;132(3):e145-e232. doi:10.2342/peds.114.2.e143

6. Cowan H. The discovery of human blood groups: Karl Otto Landsteiner. $\mathrm{Br} \quad J$ Cardiac Nursing. 2017;12(6):290-292. doi:10.12968/bjca.2017.12.6.290

7. Akkök ÇA, Seghatchian J. Immunohematologic issues in ABO-incompatible allogeneic hematopoietic stem cell transplantation. Transfus Apheresis Sci. 2018;57(6):812-815. doi:10.1016/j.transci.2018.10.020

8. Wang R, Li Y, Tong Y, Su N. Hemolytic disease of the fetus and newborn caused by anti-group A IgG from a group B mother. $J$ Pediatr Hematol Oncol. 2021;43(6):e785-e787. doi:10.1097/ MPH.0000000000001948 
9. Ree IM, Smits-Wintjens VE, van der Bom JG, van Klink JM, Oepkes D, Lopriore E. Neonatal management and outcome in alloimmune hemolytic disease. Expert Rev Hematol. 2017;10(7):607-616. doi:10.1080/17474086.2017.1331124

10. Basu S, Kaur R, Kaur G. Hemolytic disease of the fetus and newborn: current trends and perspectives. Asian J Transfus Sci. 2011;5 (1):3. doi:10.4103/0973-6247.75963

11. Kurian R. To Study the Prevalence of $A B O$ Incompatibility in $O$ Blood Group Mothers and Assessment of IgG Subclasses (IgG1 and IgG3) in them and its Correlation with Occurrence and Severity of ABO Hemolytic Disease of Newborn (ABO-HDN) in a Tertiary Health Care Centre in South India [Doctoral dissertation]. Vellore: Christian Medical College; 2020

12. Tao E, Ye D, Long G, et al. Severe neonatal anemia affected by massive fetomaternal hemorrhage: a single-center retrospective observational study. J Maternal-Fetal Neonatal Med. 2020;1-7. doi:10.1080/14767058.2020.1845313

13. Zwiers C, Scheffer-Rath ME, Lopriore E, de Haas M, Liley HG. Immunoglobulin for alloimmune hemolytic disease in neonates. Cochrane Database Syst Rev. 2018;2018(3):e235. doi:10.1002/ 14651858.CD003313.pub2

14. Calhoun DA, Mahoney DH Jr. Postnatal diagnosis and management of hemolytic disease of the fetus and newborn; 2018.

15. Pichon JBL, Riordan SM, Watchko J, Shapiro SM. The neurological sequelae of neonatal hyperbilirubinemia: definitions, diagnosis, and treatment of the kernicterus spectrum disorders (KSDs). Curr Pediatr Rev. 2017;13(3):199-209.

16. Watchko JF. Neonatal indirect hyperbilirubinemia and kernicterus. In: Christine A. Gleason and Sandra E. Juul, editor, Avery's Diseases of the Newborn. Elsevier; 2018:1198-1218.

17. Usman F, Diala UM, Shapiro S, LePichon JB, Slusher TM. Acute bilirubin encephalopathy and its progression to kernicterus: current perspectives. Res Rep Neonatol. 2018;8:33. doi:10.2147/RRN. S125758

18. Akorsu EE, Acquaye JK, Benneh AA, Oppong SA, Olayemi E. Fetomaternal hemorrhage among pregnant women in Accra, Ghana Int J Gynecol Obstet. 2019;146(3):333-338. doi:10.1002/ijgo.12890

19. Hall V, Avulakunta ID. Hemolytic Diseases of the Newborn. StatPearls [Internet]; 2021.

20. Adam DL, Bowes L, Goodyear L, Moorehead PC. Conservative management of hyperferritinemia in the fetus and newborn hemolytic disease: a case report and review of the literature. J Pediatr Hematol Oncol. 2021;43(2):73-76. doi:10.1097/MPH.0000000000001586

21. Kumawat V, Kulkarni K, Goyal M, Lokadas V. ABO hemolytic disease of the fetus and newborn; still a diagnostic dilemma: a case report. Indian J Hematol Blood Transfus. 2018;34(1):183-184. doi:10.1007/s12288-017-0792-1

22. Jain A, Malhotra S, Marwaha N, Kumar P, Sharma RR. Severe ABO hemolytic disease of fetus and newborn requiring blood exchange transfusion. Asian J Transfus Sci. 2018;12(2):176. doi:10.4103/ajts. AJTS 10617

23. Subramaniyan R. Blocked $\mathrm{D}$ in $\mathrm{RhD}$ hemolytic disease of fetus and newborn. Global J Transfus Med. 2019;4(1):114.

24. Haider M, Memon S, Tariq F, Fatima S, Hameed A. Rhesus isoimmunization: late-onset hemolytic disease of the newborn without jaundice. Cureus. 2020;12(1):111.

25. Ajmani PS. Hemolytic disease of the newborn. In: Immunohematology and Blood Banking. Singapore: Springer; 2020:103-117.

26. Bi SH, Jiang LL, Dai LY, et al. Rh-incompatible hemolytic disease of the newborn in Hefei. World J Clin Cases. 2019;7(20):3202. doi:10.12998/wjcc.v7.i20.3202

27. Singh R, Garg P, Sucheta KA, Babra M. Comparison between conventional tube method and gel card technique for blood cross-matching: a study in a tertiary care center of north India. Int J Res Pharm Sci. 2020;11(4):6500-6503. doi:10.26452/ijrps.v11i4.3529
28. Moise KJ Jr. Management of rhesus alloimmunization in pregnancy. Obstet Gynecol. 2002;100(3):600-611. doi:10.1016/s0029-7844(02) 02180-4

29. Al-Lawama M, Badran E, Ala'Elrimawi ABM, Alkhatib $H$. Intravenous Immunoglobulins as adjunct treatment to phototherapy in isoimmune hemolytic disease of the newborn: a retrospective case-control study. J Clin Med Res. 2019;11(11):760.

30. Pan J, Zhan C, Yuan T, et al. Intravenous immunoglobulin G in the treatment of $\mathrm{ABO}$ hemolytic disease of the newborn during the early neonatal period at a tertiary academic hospital: a retrospective study. J Perinatol. 2021;4:1-6.

31. AlKhater SA, Albalwi RA, Alomar SA, et al. Value of the direct antiglobulin test in predicting the need for phototherapy in newborns. J Blood Med. 2021;12:53. doi:10.2147/JBM.S291606

32. Krog GR, Donneborg ML, Hansen BM, et al. Prediction of ABO hemolytic disease of the newborn using pre-and perinatal quantification of maternal anti-A/anti-B IgG titer. Pediatr Res. 2020;15:1-8.

33. Tewari VV, Kumar A, Singhal A, et al. Evaluation of Rh-hemolytic disease in neonates and management with early intensive phototherapy in the neonatal intensive care unit. J Trop Pediatr. 2020;66(1):75-84.

34. Metcalf RA, Khan J, Andrews J, Mayock D, Billimoria Z, Pagano MB. Severe ABO hemolytic disease of the newborn requiring exchange transfusion. $J$ Pediatr Hematol Oncol. 2019;41 (8):632-634. doi:10.1097/MPH.0000000000001248

35. El Fekey SWI, El-Sharkawy HM, Ahmed AAEE, Nassar MAE, Elgendy MM. Effect of intravenous immunoglobulin in reducing bilirubin levels in hemolytic disease of newborn. Egypt J Hospital Med. 2019;74(5):957-968. doi:10.21608/ejhm.2019.25779

36. Mimura K, Endo M, Takahashi A, et al. Successful management of fetal hemolytic disease due to strong anti-Rh17 with plasma exchange and intrauterine transfusion in a woman with the $\mathrm{D}-$ - phenotype. Int J Hematol. 2020;111(1):149-154. doi:10.1007/s12185-019-02735-6

37. Steiner LA, Bizzarro MJ, Ehrenkranz RA, Gallagher PG. A decline in the frequency of neonatal exchange transfusions and its effect on exchange-related morbidity and mortality. Pediatrics. 2007;120 (1):27-32. doi:10.1542/peds.2006-2910

38. Venkataraman R, Yusuf K. Intravenous immunoglobulin in the management of a rare cause of hemolytic disease of the newborn: anti-SARA antibodies. $J$ Neonatal Perinatal Med. 2017;10 (3):329-332. doi:10.3233/NPM-16131

39. Maisonneuve E, Toly-Ndour C, Jouannic JM. Postponing early intrauterine transfusion with intravenous immunoglobulin treatment: the PETIT study on the severe hemolytic disease of the fetus and newborn. Am J Obstet Gynecol. 2019;220(3):288. doi:10.1016/j.ajog.2018.10.025

40. Hughes GO, Osman J, Coady AM, Klonin H. Acute hemoglobin increase after transfusion and immunoglobulin for rhesus hemolytic disease of the newborn. J Clin Neonatol. 2018;7(1):48. doi:10.4103/ jcn.JCN_48_17

41. Mark A, Foster AM, Grossman D, et al. Foregoing Rh testing and anti-D immunoglobulin for women presenting for early abortion: a recommendation from the National Abortion Federation's Clinical Policies Committee. Contraception. 2019;99(5):265-266. doi:10.1016/j.contraception.2019.02.008

42. de Haas M, Thurik FF, van der Ploeg CP, et al. Sensitivity of fetal $\mathrm{RhD}$ screening for safe guidance of targeted anti-D immunoglobulin prophylaxis: prospective cohort study of a nationwide programme in the Netherlands. Obstet Gynecol Surv. 2017;72(3):155-157. doi:10.1097/01.ogx.0000513227.69777.ca

43. Sahoo T, Thukral A, Sankar MJ. Delayed cord clamping in Rh-alloimunised infants: a randomized controlled trial. Eur J Pediatr. 2020;179(6):297-316. doi:10.1007/s00431-020-03578-8

44. Koelewijn JM, Slootweg YM, Folman C, van Kamp IL, Oepkes D, de Haas M. Diagnostic value of laboratory monitoring to predict severe hemolytic disease of the fetus and newborn in non-D and non-K-alloimmunized pregnancies. Transfusion. 2020;60 (2):391-399. doi:10.1111/trf.15631 
45. Slootweg YM, Lindenburg IT, Koelewijn JM, Van Kamp IL, Oepkes D, De Haas M. Predicting anti-kell-mediated hemolytic disease of the fetus and newborn: diagnostic accuracy of laboratory management. Am J Obstet Gynecol. 2018;219(4):393-e1. doi:10.1016/j.ajog.2018.07.020

46. Leafy MS, Ellarby NS. Early intravenous immunoglobulin. Eur J Pediatr. 2020;170(4):461-467. doi:10.1007/s00431-010-1310-8.Epub.2019

47. Elalfy MS. Prevention of hemolytic disease of newborn. Eur J Pediatr. 2018;170(4):461-467. doi:10.1007/s00431-010-1310-8

48. Osonoi K, Kudo K, Kobayashi A, et al. A comprehensive evaluation including ultrasound monitoring of fetal hemolytic disease in Rhesus E incompatibility. Hirosaki Med J. 2020;71(1):71-74.

49. Agrawal A, Hussain KS, Kumar A. Minor blood group incompatibility due to blood groups other than $\mathrm{Rh}$ (D) leading to hemolytic disease of the fetus and newborn: a need for routine antibody screening during pregnancy. Intractable Rare Dis Res. 2020;60:1094-2019.

50. Santavy J. Hemolytic disease in the newborn-history and prevention in the World and the Czech Republic. Biomed Pap Med Fac Univ Palacky Olomouc Czech Repub. 2010;154(2):147-151. doi:10.5507/bp.2010.022

51. Peyrard T, Pham BN, Arnaud L, et al. Fatal hemolytic disease of the fetus and newborn associated with anti-Jra. Transfusion. 2008;48 (9):1906-1911. doi:10.1111/j.1537-2995.2008.01787.x

52. Noronha SA. Acquired and congenital hemolytic anemia. Pediatr Rev. 2016;37(6):235-246. doi:10.1542/pir.2015-0053

53. Perinatal J. Intravenous Immunoglobulin G in treating ABO hemolytic disease of the newborn. Indian J Hematol Blood Transfus. 2021;132(3):e145-e232. doi:10.2342/peds.114.2.e143

54. Crowe EP, Goel R. Survey of newborn direct antiglobulin testing practice in US and Canadian transfusion services. Transfusion. 2021;120(1):27-32. doi:10.1542/peds.2006-2910

55. Wang N, Zhang L. A case of severe hemolytic disease of the newborn. $N$ Engl J Med. 2021;37(1):1775-1777. doi:10.1056/ NEJM199812103392410

56. Maisonneuve E, Dugas A, Friszer S, et al. Effect of intravenous immunoglobulins to postpone the gestational age of first intrauterine transfusion in very severe red blood cell alloimmunization: a case-control study. J Gynecol Obstet Human Reprod. 2021;50 (7):102119. doi:10.1016/j.jogoh.2021.102119
57. Bussel JB, Vander Haar EL, Berkowitz RL. New developments in fetal and neonatal alloimmune thrombocytopenia. Am J Obstet Gynecol. 2021;225:120-127. doi:10.1016/j.ajog.2021.04.211

58. Pegoraro V, Urbinati D, Visser GH, et al. Hemolytic disease of the fetus and newborn due to $\mathrm{Rh}$ (D) incompatibility: a preventable disease still produces significant morbidity and mortality in children. PLoS One. 2020;15(7):e0235807. doi:10.1371/journal. pone. 0235807

59. Bujandric N, Grujic J. Exchange transfusion for severe neonatal hyperbilirubinemia: 17 years experience from Vojvodina, Serbia. Indian $J$ Hematol Blood Transfus. 2016;32(2):208-214. doi:10.1007/s12288-015-0534-1

60. Hendrickson JE, Delaney M. Hemolytic disease of the fetus and newborn: modern practice and future investigations. Transfus Med Rev. 2016;30(4):159-164. doi:10.1016/j.tmrv.2016.05.008

61. Delaney M, Matthews DC. Hemolytic disease of the fetus and newborn: managing the mother, fetus, and newborn. Hematology. 2015;2015(1):146-151. doi:10.1182/asheducation-2015.1.146

62. Mitra S, Rennie J. Neonatal jaundice: etiology, diagnosis, and treatment. Br J Hosp Med. 2017;78(12):699-704. doi:10.12968/ hmed.2017.78.12.699

63. Fasano RM. Hemolytic disease of the fetus and newborn in the molecular era. Semin Fetal Neonatal Med. 2016;21(1):28-34. doi:10.1016/j.siny.2015.10.006

64. Quraishy N, Sapatnekar S. Advances in blood typing. Adv Clin Chem. 2016;77:221-269.

65. Chen DP, Wen YH, Lu JJ, Tseng CP, Wang WT. Rapid rare ABO blood typing using a single PCR based on a multiplex SNaPshot reaction. J Formosan Med Assoc. 2019;118(1):395-400. doi:10.1016/ j.jfma.2018.06.014

66. Zhou ZZ, Xu D, Sun L, Lan J. The progress in pre-transfusion test technique research. Asia Pac J Blood Types Genes. 2017;1:7-12.
OPediatric Health, Medicine and Therapeutics

\section{Publish your work in this journal}

Pediatric Health, Medicine and Therapeutics is an international, peerreviewed, open access journal publishing original research, reports, editorials, reviews and commentaries. All aspects of health maintenance, preventative measures and disease treatment interventions are addressed within the journal. Practitioners from all disciplines are invited to submit their work as well as healthcare researchers and patient support groups. The manuscript management system is completely online and includes a very quick and fair peer-review system. Visit http://www.dovepress.com/testimonials.php to read real quotes from published authors. 